\title{
Características de reprodução, peso ao nascer e mortalidade de caprinos Anglo-nubianos, no município do Rio de Janeiro I-Fatores que afetam o período de gestação, fertilidade e prolificidade* \\ Reproductive traits, birth weight and mortality of Anglo-nubian goats, in Rio de Janeiro I - Factors affecting the gestation period, fertility and prolificity ${ }^{\star}$
}

\author{
Luís Fernando Dias Medeiros,, ${ }^{* *}$ Debora Helena Vieira, ${ }^{* * *}$ Victor Cruz Rodrigues, ${ }^{* *}$ Celso Guimarães Barbosa, ${ }^{* * *}$ \\ Paulo Oldemar Scherer*****
}

\begin{abstract}
Resumo
Objetivou-se neste estudo avaliar o desempenho reprodutivo de um rebanho de caprinos da raça Anglo-nubiana, criados em regime semi-intensivo. A duração média do período de gestação das cabras foi de 148,46 dias. Foram verificados intervalos de 141 a 155 dias para a duração da gestação, com uma maior concentração $(65,8 \%)$ de partos entre 146 e 150 dias. O período de gestação foi influenciado significativamente pelo tipo de parição $(P<0,01)$, e pelo ano, época e ordem de parição $(P<0,05)$. Constatou-se a existência de uma relação inversa entre o número de crias e a duração da gestação. As parições ocorreram, na sua maioria, no período entre os meses de julho e outubro $(88,5 \%)$, revelando, assim, que o sistema de criação não interferiu na parição sazonal dos caprinos mantidos na região Centro-Sul do Brasil. A taxa de fertilidade foi de $80,4 \%$, a taxa de gemelidade e o índice de prolificidade foram de 52,3\% e 1,66 crias/cabras paridas, respectivamente. A taxa de fertilidade das cabras, foi influenciada significativamente $(P<0,05)$ pelo ano e época de cobertura. $O$ índice de prolificidade das matrizes foi influenciado significativamente pela época e ordem de parição $(P<0,01)$ e para o ano de parição $(P<0,05)$. $O$ método diferencial de Weinberg mostrou que a proporção de parições gemelares de origem monozigótica foi de 3,1\%.
\end{abstract}

Palavras-Chave: aspecto reprodutivo, clima tropical úmido, sistema de criação semi-intensivo

\begin{abstract}
Some reproductive aspects of a group of Anglo-nubian goats raised under semi-intensive conditions were analysed. The average duration of the frequency of the gestation period of the goats ranged from 148,46 days. Intervals ranging from 141 to 155 days were verified to the gestation period, with a higher concentration $(65,8 \%)$ between 146 and 150 days. The gestation period was significantly influenced by parturition type $(P<0,01)$, and by year, season and parturition order $(P<0,05)$. It was verified the existence of an inverse relation between the number of newborns and the gestation duration. Parturition ocurred mostly between july and october $(88,5 \%)$, revealing therefore that the raising creation system did not interfeer in the sazonal parturition of the goats kept in Southern Central Brazil. The fertility percentual at birth was $80,4 \%$, twin birth percentual and prolificity index were $52,3 \%$ and 1,66 kids/calving doe, respectively. The fertility percentual of goats was significant influenced $(P<0,05)$ by year and covering season. The prolificity index of goats was significant influenced by season and parturition order $(P<0,01)$ and by parturition year $(\mathrm{P}<0,05)$. The Weinberg method showed that the proportion of twin parturition of monozigotic origin was $3,1 \%$.
\end{abstract}

Keywords: humity tropical region, reprotuctive aspect, semi-intensive system

\section{Introdução}

O reconhecimento precoce da prenhez é de considerável interesse econômico pois permite reduzir o intervalo de partos, o desgaste de reprodutores e de rufiões; permite o diagnóstico de infertilidade ou subfertilidade bem como viabiliza o arraçoamento econômico de cabras gestantes (Simplício et al., 1990; Ribeiro, 1998).

* Parte da dissertação de Mestrado em Zootecnia, apresentada à Universidade Federal Rural do Rio de Janeiro - UFRuralRJ, pelo primeiro autor.

** Departamento de Reprodução e Avaliação Animal, Instituto de Zootecnia - UFRuralRJ. BR 465 Km 7, Seropédica, RJ - CEP $23851-970$ (email: diasmedeiros@yahoo.com.br).

*** Consultora Técnica na Área de Produção Animal (e-mail: deborahelenavieira@yahoo.com.br).

**** Departamento de Matemática, Instituto de Ciências Exatas - UFRuralRJ (e-mail: celsogb@ufrrj.br).

***** Departamento de Anatomia Animal, Instituto de Biologia - UFRuralRJ. 
Quando a taxa de fertilidade é baixa, indica que o número de animais efetivamente se reproduzindo está abaixo do número potencial e fatalmente ocorrerá impacto sobre a idade ao primeiro parto e o intervalo de partos (Simplício et al., 1990; Gonçalves, 1996; Ribeiro, 1998; Ribeiro et al., 1999).

A prolificidade é uma característica de ordem fisiológica com variações dentro da espécie e da raça. O índice de prolificidade, quando associado à fertilidade ao parto, é uma medida importante para se determinar a eficiência produtiva e reprodutiva do rebanho (Simplício et al., 1990; Ribeiro, 1998; Medeiros et. al., 2001).

Na região Sudeste e demais núcleos de caprinos do país, a raça Anglo-nubiana (tronco africano) está sendo difundida, sendo ainda restritos os estudos conduzidos com o objetivo de se conhecer o seu comportamento e, conseqüentemente, suas potencialidades. Em razão disso, há poucas informações sobre a produtividade dessa raça, em termos de região Sudeste, particularmente no estado do Rio de Janeiro.

O objetivo do presente trabalho foi avaliar o comportamento reprodutivo de um rebanho caprino da raça Anglo-nubiana, criado em regime semi-intensivo, no município do Rio de Janeiro, estado do Rio de Janeiro.

\section{Material e métodos}

Os dados utilizados neste estudo referem-se a um criatório de caprinos localizado na Zona Oeste do município do Rio de Janeiro, estado do Rio de Janeiro. De acordo com a classificação climática de Köppen, o clima é descrito como Aw, do tipo quente e úmido (tropical úmido), com chuvas de verão e estiagem no inverno. Durante os anos de estudo (1981 e 1992), a temperatura média foi de $23,7^{\circ} \mathrm{C}$; a umidade relativa média foi de $79 \%$ e a precipitação anual média de $1.275 \mathrm{~mm}$.

Foram utilizados neste trabalho caprinos de um plantel da raça Anglo-nubiana de aptidão mista (leite e carne), destinado à venda de reprodutores e matrizes.

O sistema de criação era o semi-intensivo onde os animais eram alimentados à base de capim-elefante (Pennisetum purpureum Schum), capim-colonião (Panicum maximum Jacq.), capim-jaraguá (Hyparrhenia rufa (Ness) Stapf), feno de alfafa (Medicago sativa), com suplementação de ração comercial e sal mineral, durante todos os meses do ano.

O manejo sanitário era realizado de acordo com as normas vigentes na ocasião.

A amamentação era natural contínua apenas na primeira semana de idade: a partir da segunda semana em diante, a amamentação era natural controlada (as crias tinham acesso à mãe duas vezes ao dia, pela manhã e à tarde) e artificial, onde as crias recebiam leite de vaca oferecido em mamadeiras individuais. Esse procedimento foi até os 90 dias de idade; a partir desta data até o desmame (150 dias) as crias recebiam apenas o aleitamento artificial.

A partir da segunda semana de vida, as crias tinham acesso ao pasto, além de receberem sal mineral, água à vontade, feno de alfafa (Medicago sativa) e, a partir da quarta semana, recebiam ração comercial (16\% de PB e $2.600 \mathrm{kcal})$ em quantidades crescentes.

O período da estação de cobertura compreendia o final do verão, outono e início do inverno, época em que ocorre diminuição do comprimento do dia. Não foi utilizado o sistema de reprodução programada composto pela indução do cio com luz artificial nos meses em que as fêmeas se apresentavam com anestro funcional.

Ao longo de 12 anos (1981 e 1992), foram analisados os seguintes parâmetros: período de gestação (dias), fertilidade (\%), prolificidade (crias por cabra parida), gemelidade (\%) e proporção sexual (\%).

O período de gestação (675 observações) foi obtido de 82 cabras e analisado segundo o ano de parição (1981 a 1992), época de parição (período das "águas" e período das "secas"), ordem de parição (1 $1^{\underline{a}}$ a $9^{a}$ ) e tipo de parição (simples, duplo, triplo ou quádruplo). Foi considerado como período das "águas" os meses de outubro a abril, e das "secas", os meses de maio a setembro.

Foi calculada também a distribuição das parições em relação aos meses do ano, sendo que os dados utilizados abrangeram as 675 informações de parições.

A fertilidade foi calculada dividindo-se o número de partos pelo número de fêmeas em idade reprodutiva e multiplicandose por 100, para obter o resultado em porcentagem. Esse parâmetro foi analisado estatisticamente considerando-se como fonte de variação o ano de cobertura, a época de cobertura e a ordem de parição. A prolificidade foi calculada dividindose o número de crias pelo número de partos. Para essa característica utilizaram-se os nascimentos de 1.123 cabritos oriundos de 675 parições. Essa característica foi analisada considerando-se o possível efeito do ano de parição, época de parição e ordem de parição das matrizes.

Considerando-se que o efeito ambiente teria maior influência em relação ao aumento da taxa ovulatória (parições dizigóticas), ao passo que as parições monozigóticas sofreriam maior influência do patrimônio genético, determinou-se a incidência de partos gemelares, aplicandose o método de Weinberg (Hogben, 1946). De acordo com o método diferencial de Weinberg, o número total de pares dizigóticos será considerado como o dobro do número de pares discordantes quanto ao sexo, enquanto o número de monozigóticos será obtido pela diferença entre o total de gêmeos e o de pares dizigóticos.

O delineamento experimental utilizado foi o inteiramente casualisado.

Para a análise de variância dos dados, foi utilizado o método dos mínimos quadrados segundo Harvey (1987). A comparação das médias foi realizada pelo teste de Tukey a $5 \%$ de probabilidade.

Os modelos estatísticos usados na análise das características reprodutivas foram:

a) Período de gestação

$Y_{i j k l m}=m+A_{i}+E_{j}+O_{k}+T_{1}+e_{i j k l m}$

Onde:

$Y_{\mathrm{ijklm}}=$ período de gestação;

$\mathrm{m}=$ constante inerente a todas as observações;

$A_{i}=$ efeito do ano de parição (1981 a 1992);

$E_{j}=$ efeito da época de parição (período das "águas" e das "secas"); 


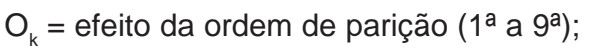

$\mathrm{T}_{1}=$ efeito do tipo de parição (simples, duplos, triplos e quádruplos);

$\mathrm{e}_{\mathrm{ijk} \mid \mathrm{m}}=$ erro aleatório a cada observação, suposto de distribuição normal e independente.

b) Fertilidade

$Y_{i j k l}=m+A_{i}+E_{j}+O_{k}+e_{i j k l}$

Onde:

$\mathrm{Y}_{\mathrm{ijk}}=$ taxa de fertilidade (classificada como zero = insucesso e

1 = sucesso);

$\mathrm{m}=$ constante inerente a todas as observações;

$A_{i}=$ efeito do ano de cobertura (1981 a 1992);

$E_{j}=$ efeito da época de cobertura (período das "águas" e das "secas");

$\mathrm{O}_{\mathrm{k}}=$ efeito da ordem de parição ( $1^{\mathrm{a}}$ a $\left.9^{\mathrm{a}}\right)$;

$\mathrm{e}_{i \mathrm{ikl}}=$ erro aleatório a cada observação, suposto de distribuição normal e independente.

c) Prolificidade

$Y_{i j k l}=m+A_{i}+E_{j}+O_{k}+e_{i j k l}$

Onde:

$\mathrm{Y}_{\mathrm{ijkl}}=$ prolificidade, tomada como 1 ou 2 ou 3 ou 4;

$\mathrm{m}=$ constante inerente a todas as observações;

$A_{i}=$ efeito do ano de parição (1981 a 1992);

$E_{j}=$ efeito da época de parição (período das "águas" e das "secas");

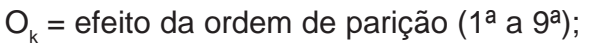

$\mathrm{e}_{i \mathrm{ijk}}=$ erro aleatório a cada observação, suposto de distribuição normal e independente.

\section{Resultados e discussão}

\section{Período de Gestação}

$\mathrm{O}$ ano de parição influenciou significativamente $(\mathrm{P}<0,05)$ o período de gestação das cabras (Tabela 1). Esse fato foi verificado por Medeiros et al. (2001) em caprinos Anglonubianos, e por Rodrigues de Medeiros et al. (1997) em caprinos da raça Canindé e Anglo-nubiana. Por outro lado, é diferente dos resultados obtidos por esse último autor, com cabras da raça Alpina, quando o período de gestação não foi influenciado pelo ano de parição.

Uma série de fatores como alteração etária do rebanho, melhorias das condições de alimentação e sanidade, além de um possível efeito genético, podem ter influenciado o ano de parição como fonte de variação do período de gestação destas cabras. Todavia, é possível que pelo menos em parte, as variações na disponibilidade de forragens, devido às precipitações pluviais através dos anos de estudo, tenham influenciado o período de gestação das cabras, mesmo havendo uma moderada variação nos índices pluviométricos ao longo dos anos.
Tabela 1: Análise de variância para o período de gestação (PG), fertilidade $(F)$ e prolificidade $(P)$, de cabras da raça Anglonubiana

\begin{tabular}{lcccc}
\hline Fonte de variação & GL & \multicolumn{3}{c}{ Quadrado médio } \\
\cline { 3 - 5 } & & PG & F & P \\
\hline Ano de parição & 11 & $304,92^{*}$ & - & $21,464^{*}$ \\
Ano de cobertura & 11 & - & $4,024^{*}$ & - \\
Época de parição & 1 & $114,07^{*}$ & - & $102,343^{* *}$ \\
Época de cobertura & 1 & - & $0,978^{*}$ & - \\
Ordem de parição & 8 & $57,71 *$ & $1,656 \mathrm{~ns}$ & 24,869 ** \\
Tipo de parição & 3 & 308,63 ** & - & - \\
Resíduo & & 5,11 & 0,510 & 8,305 \\
& (a) & $(651)$ & $(819)$ & $(654)$ \\
Total & (b) & $(674)$ & $(839)$ & $(674)$ \\
\hline CV \% & & & & \\
\hline
\end{tabular}

(a) = Número entre parênteses representa os graus de liberdade do resíduo. (b) = Número entre parênteses representa os graus de liberdade do total.

* = Significativo $(\mathrm{P}<0,05)$

** $=$ Significativo $(\mathrm{P}<0,01)$

ns $=$ não significativo $(P>0,05)$

A média do período de gestação das cabras oscilou de 146,47 em 1981 a 149,41 dias em 1986. As médias obtidas para os primeiros cinco anos do trabalho (1981 a 1985) foram inferiores aos dos anos subseqüentes (Tabela 2). Tal fato pode ser atribuído, em parte, às melhorias da alimentação e aspectos sanitários do rebanho.

A época de parição teve influência significativa $(P<0,05)$ sobre o período de gestação das cabras (Tabela 1). A média do período de gestação das cabras que procriaram no período das "águas" foi maior que aquelas que procriaram no período das "secas", respectivamente, de 149,12 e 147,80 dias (Tabela 2). Esta tendência também foi notada por Rodrigues de Medeiros et al. (1997) e Medeiros et al. (2001). Por outro lado, Medeiros et al. (1991) citaram que o mês, assim como a estação das "águas" e das "secas" não tiveram influência sobre o período de gestação, em cabras Anglo-nubianas, suplementadas no período da estiagem.

Mesmo as cabras recebendo suplementação alimentar durante todos os meses do ano, o período médio de gestação daquelas paridas na metade do período das "águas" (Tabela 2) foi maior do que aquelas que procriaram no período das "secas". Em parte a maior disponibilidade das forragens, já no início do período das "águas", foi responsável por um período de gestação mais longo, melhorando o estado nutricional das cabras, preparando melhor o feto.

A ordem de parição influenciou significativamente $(P<0,05) \circ$ período de gestação das cabras (Tabela 1). Esta mesma tendência foi observada por Qureshi et al. (1991) em cabras da raça Malvi, Medeiros et al. (1991 e 2001) e Rodrigues de Medeiros et al. (1997), ambos com caprinos Anglo-nubianos. Por outro lado, foi diferente dos resultados obtidos por este último autor, quando a ordem de parição não teve influência significativa em relação à raça Alpina. 
Tabela 2: Médias observadas para o período de gestação $(P G)$, taxa de fertilidade $(F)$ e índice de prolificidade $(P)$, de cabras da raça Anglo-nubiana

\begin{tabular}{|c|c|c|c|}
\hline \multirow[t]{2}{*}{ Fontedevariação } & \multicolumn{3}{|c|}{ Médiaobservada } \\
\hline & PG & $\mathbf{F}^{(1,2)}$ & $\mathbf{P}$ \\
\hline Média geral & 148,46 & 80,47 & 1,66 \\
\hline \multicolumn{4}{|l|}{$\begin{array}{l}\text { Ano de parição } \\
(\text { Ano de cobertura) })^{\left({ }_{1}\right)} \text { : }\end{array}$} \\
\hline 1981 & $146,47 c$ & $70,55 d$ & $1,55 \mathrm{e}$ \\
\hline 1982 & $147,60 \mathrm{ab}$ & $72,75 d$ & $1,57 e$ \\
\hline 1983 & $147,64 a b$ & $75,63 c$ & $1,60 d$ \\
\hline 1984 & $147,31 b$ & $77,80 \mathrm{bc}$ & $1,62 d$ \\
\hline 1985 & $147,87 a b$ & $76,30 \mathrm{bc}$ & $1,65 c$ \\
\hline 1986 & $149,41 \mathrm{a}$ & $78,15 b$ & $1,66 b c$ \\
\hline 1987 & $149,00 a$ & $80,25 b$ & $1,70 b$ \\
\hline 1988 & $148,08 a b$ & $80,17 b$ & $1,68 b$ \\
\hline 1989 & $147,90 a b$ & $82,74 b$ & 1,73ab \\
\hline 1990 & $148,93 a$ & $89,75 a$ & $1,76 a$ \\
\hline 1991 & $149,14 a$ & $91,35 a$ & $1,75 a$ \\
\hline 1992 & $149,28 a$ & $90,20 a$ & $1,78 a$ \\
\hline \multicolumn{4}{|l|}{$\begin{array}{l}\text { Época de parição } \\
(\text { Epoca de cobertura })^{(2)} \text { : }\end{array}$} \\
\hline "Secas" & $147,80 b$ & $77,16 b$ & $1,70 b$ \\
\hline "Áquas" & $149,12 a$ & $83,78 a$ & $1,60 \mathrm{a}$ \\
\hline \multicolumn{4}{|l|}{ Ordem de parição: } \\
\hline $1^{\mathrm{a}}$ & $146,98 c$ & - & $1,55 d$ \\
\hline $2^{a}$ & $147,90 b$ & - & $1,58 \mathrm{~d}$ \\
\hline $3^{a}$ & $148,15 a b$ & - & $1,65 c$ \\
\hline $4^{a}$ & $148,31 \mathrm{ab}$ & - & $1,70 b$ \\
\hline $5^{a}$ & $147,98 a b$ & - & $1,78 a$ \\
\hline $6^{a}$ & $148,04 a b$ & - & $1,72 b$ \\
\hline $7^{\mathrm{a}}$ & $149,00 a b$ & - & $1,65 c$ \\
\hline $8^{a}$ & $149,88 a$ & - & $1,62 \mathrm{~cd}$ \\
\hline $9^{a}$ & $148,75 a b$ & - & $1,60 \mathrm{~cd}$ \\
\hline \multicolumn{4}{|l|}{ Tipo de parição: } \\
\hline Simples & $149,50 a$ & - & - \\
\hline Duplo & $147,78 b$ & - & - \\
\hline Triplo & $145,20 c$ & - & - \\
\hline Quádruplo & $142,83 d$ & - & - \\
\hline
\end{tabular}

Nota: Médias seguidas de mesma letra dentro de cada fator de classificação não diferem significativamente entre si pelo teste de Tukey a $5 \%$.

${ }^{(1,2)}=\mathrm{O}$ número entre parênteses indica a fonte de variação, ano de cobertura e época de cobertura na análise do parâmetro fertilidade.

Foram observadas variações nas médias do período de gestação das matrizes em razão da ordem de parição (Tabela 2). Cabras de primeira e segunda parição apresentaram um período de gestação mais curto quando comparadas ao das cabras de ordens de parições superiores. Uma explicação provável para esse fato é que, por estarem em desenvolvimento, as mães jovens necessitam de maior porção de nutrientes do que as adultas, e por isso sobra menos nutrientes para o desenvolvimento do feto, o que pode diminuir em média o período de gestação dessas cabras.

Constatou-se uma influência significativa $(P<0,01)$ do tipo de parição sobre o período de gestação das cabras (Tabela 1). A média do período de gestação das cabras que tiveram partos simples foi superior àquelas que tiveram partos múltiplos (Tabela 2). A explicação provável é que o ambiente uterino é um fator limitante concorrendo para a diminuição do período de gestação de cabras com partos múltiplos. Observou-se que, à medida que aumentou o número de produtos por concepção, diminuiu o período de gestação das cabras. Essa tendência é citada na literatura (Rodrigues, 1988; Medeiros et al., 1991 e 2001; Qureshi et al., 1991; Rodrigues de Medeiros et al., 1997), em caprinos de diferentes tipos raciais, entre esses o Anglo-nubiano. Contudo, Moulin e Mouchrek (1987) não observaram a influência do tipo de parto sobre o período de gestação em cabras sem raça definida (SRD).

O período médio de gestação das cabras Anglo-nubianas obtido neste estudo foi de 148,46 dias (Tabela 2). Este valor está em consonância com aqueles obtidos por Rodrigues (1988), Dickson et al. (1990), Medeiros et al. (1991 e 2001) e Rodrigues de Medeiros et al. (1997), em caprinos da raça Anglo-nubiana puros e mestiços.

Foi verificado um intervalo de 141 a 155 dias para o período de gestação, com uma maior concentração $(65,8 \%)$ de partos entre $0146^{\circ}$ e $150^{\circ}$ dia, conforme consta na Tabela 3. A magnitude do período de gestação das cabras obtida neste trabalho mostrou-se semelhante à descrita por Medeiros et al. (1991 e 2001) em caprinos Anglo-nubianos, que foram respectivamente, de um período mínimo de 141 e 142 dias e de um máximo de 155 e 156 dias para os dois trabalhos, sendo que $57,4 \%$ e $64,0 \%$ dos períodos de gestação ocorreram na faixa de 146 a 150 dias, para a mesma ordem.

As fontes de variação estudadas podem ter sido responsáveis, em parte, por este intervalo de 141 a 155 dias (14 dias) para o período de gestação destas cabras (Tabela 3). Todavia, a literatura (Vieira et al., 1987; Simplício et al., 1990; Ribeiro, 1998), tem citado intervalos superiores a 20 dias no período de gestação em caprinos.

Tabela 3: Freqüência de distribuição do período de gestação (PG) de caprinos da raça Anglo-nubiana.

\begin{tabular}{ccc}
\hline PG (dias) & № de observações & Freqüência (\%) \\
\hline $141-145$ & 113 & 16,7 \\
$146-150$ & 444 & 65,8 \\
$151-155$ & 118 & 17,5 \\
\hline
\end{tabular}

\section{Fertilidade}

O efeito do ano sobre a taxa de fertilidade das cabras foi significativo $(P<0,05)$, conforme consta na Tabela 1, fato este relatado por Rodrigues (1988), Medeiros et al. (1991) e Ribeiro et al. (1999), em caprinos de diferentes tipos raciais. A taxa de fertilidade verificada neste trabalho foi de $80,4 \%$. Ao longo dos 12 anos de observações, foram encontradas variações de 70,5 a $90,2 \%$ na taxa de fertilidade das matrizes (Tabela 2). A taxa de fertilidade de $80,4 \%$, encontrada neste trabalho, está em acordo com as citadas por Medeiros et al. (1991, 1992 e 1998) em caprinos Anglo-nubianos, e Maia e Costa (1997) em cabras da raça Canindé.

Houve um acréscimo dos níveis de fertilidade durante os anos de estudo, sendo que as taxas mais baixas foram obtidas nos dois primeiros anos, conforme a Tabela 2. Este aumento da taxa de fertilidade através dos anos, provavelmente foi devido à melhoria das condições de alimentação e manejo sanitário do rebanho, durante os anos do estudo. É possível que, pelo menos em parte, as variações na disponibilidade das forragens, devido as flutuações nos índices pluviométricos 
através dos anos de estudo, podem ter influenciado a taxa de fertilidade das cabras.

Houve influência significativa $(P<0,05)$ da época de cobertura sobre o taxa de fertilidade das cabras (Tabela 1), fato esse também relatado por Ribeiro et al. (1999).

As médias das taxas de fertilidade obtidas nos anos de estudo foram de $83,7 \%$ e $77,1 \%$ para a época das "águas" e das "secas", respectivamente (Tabela 2). Esta inclinação, provavelmente, foi conseqüência da estação de cobertura ter iniciado no final do período das "águas", e ser o início da estação de monta principal da espécie caprina nesta região do país. Havendo nesta ocasião, uma maior disponibilidade de forragens estimulada pelo regime pluvial, coincidindo com a manifestação do estro à medida que diminuiu o comprimento do dia, como conseqüência da maior atividade ovariana durante a estação de reprodução principal.

As parições ocorreram, na sua maioria, no período entre os meses de julho a outubro (88,5\%); contudo, $100 \%$ das parições ocorreram no segundo semestre de cada ano (Figura 1), revelando que o sistema de criação não interferiu na parição sazonal dos caprinos criados na região Centro-Sul do país, observando-se a incidência de estros cobertos, quando o fotoperíodo foi decrescente. Esse comportamento também foi relatado por Bento (1985), Moulin e Mouchrek (1987), Simplício et al. (1990), Soares Filho et al. (2001) e Medeiros et al. (2001) em caprinos. Não foi notado estro durante o segundo semestre do ano, embora houvesse disponibilidade de alimentos e registros de precipitações pluviométricas a partir de outubro. Essa tendência também foi notada por Moulin e Mouchrek (1987) e Medeiros et al. (1991, 1998 e 2001).

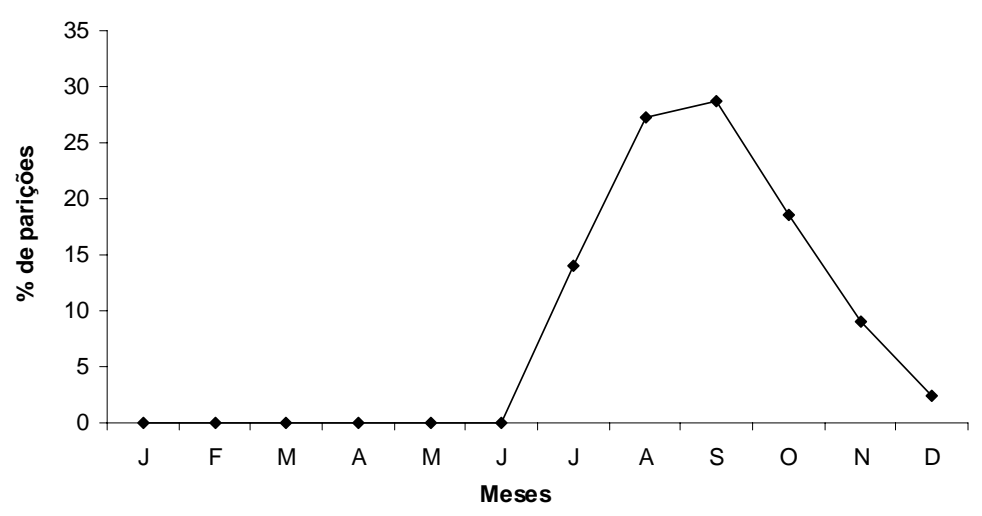

Figura 1: Distribuição das parições em cabras da raça Anglo-nubiana durante o ano.

Em razão do comportamento reprodutivo apresentado por essas cabras, o intervalo entre a parição e a próxima cobertura fértil foi em média de seis meses. Aquelas que pariram no início da estação de parição tiveram um intervalo maior do que aquelas que conceberam no final da estação; sendo que, algumas que pariram no terço final da primavera, não apresentaram estro no início da estação principal de acasalamento, pelo menos em parte, por estarem amamentando suas crias (até 90 dias de idade).

A amamentação controlada pode ter sido, em parte, a causa da infertilidade (instabilidades hormonais e a falha na ovulação) dessas cabras que não tiveram coberturas férteis no terço final do verão e no primeiro terço do outono. Além de outros fatores (genéticos e ambientais) e suas interações, atuando através de mecanismos fisiológicos com elevada participação do sistema endócrino, interferindo no processo reprodutivo das fêmeas que não desenvolveram gestação após a cobertura, contribuindo para falha de fertilização ou perda prematura de embriões (Simplício et al., 1990; Maia e Costa, 1997).

O estresse causado pela alta temperatura ambiente, já no terço final da primavera, até o início da estação de monta principal, final do verão nesta região, pode também ter influenciado na fertilização, diminuindo a taxa de concepção e aumentando a mortalidade embrionária em algumas cabras.

Não foi observado o efeito significativo $(P>0,05)$ da ordem de parição sobre a fertilidade das cabras (Tabela 1). Todavia, as menores taxas de fertilidade foram notadas nas cabras primíparas e secundíparas e com as ordens de parição mais altas (oitava e nona). Provavelmente, as matrizes mais novas não tinham atingido o peso da maturidade e as mais velhas já estavam no final da vida útil reprodutiva (Tabela 2). Contudo, Simplício et al. (1990) e Ribeiro (1998), reportam que a idade ou a ordem de parição influencia a taxa de fertilidade em caprinos.

\section{Prolificidade}

$\mathrm{O}$ ano de parição exerceu influência significativa $(\mathrm{P}<0,05)$ sobre a prolificidade das cabras (Tabela 1). Essa situação tem sido relatada pela literatura (Vieira et al., 1987; Simplício et al., 1990; Sanches Roda et al., 1995; Rodrigues de Medeiros et al., 1997; Medeiros et al., 1998; Silva e Araújo, 2000) em caprinos de vários tipos raciais.

A prolificidade média para os 12 anos de observações foi de 1,66 cabrito nascido por cabra parida (Tabela 2). Durante os anos de observação, foram encontradas variações de 1,55 a 1,78 nos índices de prolificidade do rebanho, para os anos de 1981 e 1992, respectivamente (Tabela 2). Mesmo havendo moderada variação na precipitação pluviométrica durante os anos de estudo, provavelmente houve reflexo, mesmo que discreto, na disponibilidade de forragens, influenciando a prolificidade das cabras.

Ao longo dos anos, observou-se aumento gradual da prolificidade média das cabras, sendo notada uma tendência à estabilização do índice de prolificidade, a partir de 1987 (Tabela 1), com uma média acima de 1,70 cria por parto. O índice de prolificidade registrado neste estudo está em consonância com aqueles obtidos pela literatura (Rodrigues, 1988; Sanches Roda et al., 1995; Medeiros et al., 1998; Ribeiro et al., 1999; Silva e Araújo, 2000; Souza, 2001) em caprinos de diferentes tipos raciais.

Os índices mais baixos $(1,55$ e 1,57) foram registrados nos dois primeiros anos (1981 e 1982) do estudo (Tabela 2). Provavelmente a baixa idade das cabras neste período foi uma das causas dos menores índices de prolificidade comparados aos anos subseqüentes, visto que, por ocasião da formação deste rebanho, quase todas as matrizes eram jovens, com baixo peso corporal em média, púberes e nulíparas, sendo que algumas dessas foram adquiridas em 
estado de prenhez. Por conseguinte, a maioria das parições ocorridas nos dois primeiros anos do trabalho foram oriundas das cabras primíparas. O aumento da taxa de prolificidade através dos anos do referido estudo, não só foi devido em parte da ordem de parição (Tabela 1) e sim, da melhoria das condições de alimentação e dos aspectos sanitários do rebanho, nos anos de estudo.

A época de parição influenciou significativamente $(\mathrm{P}<0,01)$ o índice de prolificidade das cabras (Tabela 1). Esse fato também foi citado por Rodrigues (1988) e Sanches Roda et al. (1995), em cabras de diferentes tipos raciais.

Durante os anos do referido estudo, animais que pariram no período das "secas" tiveram maior prolificidade comparados aos que pariram nas "águas". Provavelmente este fato pode ser devido à suplementação na época de outono/inverno e durante a gestação. Além disso, na primeira metade, algumas vezes até dois terços, do outono, os pastos ainda apresentavam boas condições de forragens, e, pelo menos em parte, pelo efeito do fotoperiodismo como conseqüência, da maior atividade ovariana durante a estação de reprodução principal da espécie, nessa região do país.

A boa prolificidade observada neste estudo, levando-se em consideração a capacidade ovulatória da cabra, pode ser atribuída à época de acasalamento principal da espécie, pois sabe-se que, quando as cabras estão em faixa ascendente de ganho de peso, a taxa ovulatória pode aumentar, já que a estação de reprodução principal ocorre, efetivamente, no final do verão e outono, havendo disponibilidade de forragens, até os dois primeiros terços do outono, na região Centro-Sul do país.

A análise de variância revelou que a prolificidade foi influenciada significativamente $(P<0,01)$ pela ordem de parição das cabras (Tabela 1). Esta tendência também foi notada por Vieira et al. (1987) em caprinos da raça Moxotó, e Ribeiro et al. (1999) em cabras européias do subtronco alpino.

Neste estudo, o aumento da prolificidade foi devido, pelo menos em parte, à maior maturidade fisiológica das matrizes mais velhas em relação às mais jovens. $O$ desenvolvimento do aparelho reprodutivo nas fêmeas jovens, ainda, pode se apresentar incompleto. Neste caso, há ocorrência de malformação dos gametas femininos. Contudo, as fêmeas mais velhas apresentaram falhas de concepção e/ou gestação, causadas pelo quadro de envelhecimento dos órgãos reprodutivos. Esta tendência pode ser observada na Figura 2 e Tabela 2, onde menores índices de partos gemelares foram obtidos em cabras de primeira e segunda ordem, e oitava e nona ordem, parições estas oriundas de cabras jovens e velhas, respectivamente.

Como reflexo da fertilidade e da prolificidade deste rebanho, as taxas de partos gemelares aumentaram durante os anos de estudo à medida que aumentou a ordem de parição, declinando consideravelmente a partir da sétima parição (Figura 2). A taxa média de partos gemelares encontrada durante os anos de estudo, foi de $52,3 \%$. As taxas de partos gemelares variaram de 40,3 a 64,8\% para a primeira e quinta ordem de parição, respectivamente. Esta inclinação pode ser

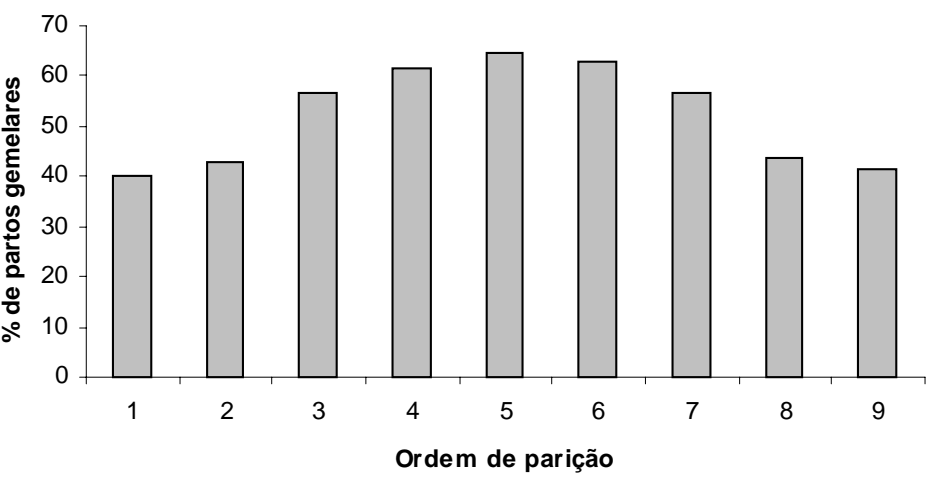

Figura 2: Percentual de parições gemelares em cabras da raça Anglo-nubiana, em função da ordem de parição.

observada na Figura 2. O valor médio de partos gemelares encontrado neste trabalho (52,3\%), está em consonância com os valores observados por Moulin e Mouchrek (1987), Vieira et al. (1987), Medeiros et al. (1991), Maia e Costa (1997) e Silva e Araújo (2000).

De um total de 675 partos, 276 parições foram simples (40,9\%) e 399 múltiplos (59,1\%). Das parições múltiplas, 353 foram gemelares (88,5\%), 43 triplos $(10,8 \%)$ e 3 quádruplos $(0,7 \%)$. Do total das parições, $52,3 \%$ foram gemelares, $6,4 \%$ triplos e $0,4 \%$ quádruplos. Esta mesma tendência foi notada no trabalho de Maia e Costa (1997) e Medeiros et al. (1998), em caprinos da raça Canindé e Anglo-nubiana, respectivamente. Por outro lado, foi diferente dos resultados obtidos por Sanches Roda et al. (1995), em cabras Anglo-nubianas, no que se refere a partos simples $(57,9 \%)$ e duplos $(40,8 \%)$.

Segundo Gonçalves (1996), o aumento do número de cabritos nascidos por ano possibilita uma maior intensidade de seleção e, conseqüentemente, maiores ganhos genéticos são esperados, mesmo sendo esta característica de baixa herdabilidade e repetibilidade.

Das parições múltiplas, 353 foram duplas (81 pares macho/ macho, 171 pares macho/fêmea e 101 pares fêmea/fêmea), 43 triplas (13 pares macho/macho/macho, 11 pares macho/ macho/fêmea, 11 pares macho/fêmea/fêmea e 8 pares fêmea/ fêmea/fêmea) e três parições quádruplas (um par macho/ macho/macho/fêmea, um par macho/macho/fêmea/fêmea, e um par macho/fêmea/fêmea/fêmea), visto na Tabela 4.

Tabela 4: Tipo de parição e número de crias em relação ao sexo, em cabras da raça Anglo-nubiana

\begin{tabular}{lccc}
\hline & Machos & Fêmeas & Total \\
\hline Simples & 132 & 144 & 276 \\
Múltiplos: & 162 & - & 162 \\
Macho - Macho & 171 & 171 & 342 \\
Macho - Fêmea & - & 202 & 202 \\
Fêmea - Fêmea & 39 & - & 39 \\
Macho - Macho - Macho & 22 & 11 & 33 \\
Macho - Macho - Fêmea & 11 & 22 & 33 \\
Macho - Fêmea - Fêmea & - & 24 & 24 \\
Fêmea - Fêmea - Fêmea & 3 & 1 & 4 \\
Macho - Macho - Macho - Fêmea & 2 & 2 & 4 \\
Macho - Macho - Fêmea - Fêmea & 1 & 3 & 4 \\
Macho - Fêmea - Fêmea - Fêmea & $\mathbf{5 4 3}$ & $\mathbf{5 8 0}$ & $\mathbf{1 1 2 3}$ \\
\hline Total & & &
\end{tabular}


$\mathrm{Na}$ amostragem de gêmeos, a freqüência de machos (proporção sexual) foi de 333/706 =0,4716 + 0,0310 (47,2\%). $\mathrm{Na}$ amostra total, a proporção sexual, expressa como porcentagem de machos, foi de 543/1123 =0,4835 $\pm 0,0210$ (48,3\%). Na amostra de cabritos machos de parições simples, a proporção foi 132/276 = 0,4782 \pm 0,0221 (47,8\%).

Aplicando-se o teste de Weinberg (Hogben, 1946) para os partos gemelares, obteve-se uma freqüência de partos gemelares monozigóticos de $3,1 \%$. Este resultado foi muito próximo dos registrados por Sanches Roda et al. (1995) e Medeiros et al. (1998 e 2004) em caprinos da raça Anglonubiana, que aplicando o mesmo teste, obtiveram uma freqüência de $3,0,2,8$ e 3,3\% de partos gemelares, respectivamente.

\section{Conclusões}

Os resultados observados no presente estudo conduzem às seguintes conclusões:

\section{Referências}

BENTO, A. H. L. Algumas observações sobre comportamento produtivo de cabras. 1. Desempenho produtivo de cabras importadas da raça Parda Alemã, criados em confinamento em Maricá, RJ. Rev. Bras. Med. Vet., v. 7, n. 2, p. 35-36, 1985.

DICKSON, L.; GARCIA, B. E.; RIVERO, R. Comportamiento productivo y reproductivo de cabras Nubian y Alpino Francés. In: CONGRESO VENEZOLANO DEZOOTECNIA, 6. Venezuela. Univ. Nac. del Tachira. 1990.

GONÇALVES, H. C. Fatores genéticos e de meio em algumas características produtivas e reprodutivas de caprinos. Viçosa, MG, UFV. Tese de Doutorado, 141 p. 1996.

HARVEY, W. User's guide for LSMLMV-Mixed Model Least Squares and Maximum Likelehood Computer Program. Wooster, Ohio State University, 59 p., 1987.

HOGBEN, L. An introduction to mathematical genetics. Norton, New York, 260 p., 1946.

MAIA, M.; COSTA, A. N. Avaliação do desempenho reprodutivo de um rebanho de cabras da raça Canindé, na Zona Semi-árida do Rio Grande do Norte. Rev. Bras. Zootec, v. 26, n. 1, p. 46-53, 1997.

MEDEIROS, L. F. D.; COUTINHO, L. de S.; SOUSA, J. C. D. de; LISEU, L. C. Avaliação de alguns caracteres reprodutivos de caprinos Anglonubianos, no Estado do Rio de Janeiro. Arq. Univ. Fed. Rur. Rio de Janeiro, Itaguaí, v. 14, n. 1, p. 65-82, 1991.

MEDEIROS, L. F. D.; SOUSA, J. C. D. de; COUTINHO, L. de S.; LISEU, L. C. Estudo comparativo do crescimento de cabritos Anglo-nubianos, SRD (Sem Raça Definida) e meio Anglo-nubiano x SRD. Arq. Univ. Fed. Rur. Rio de Janeiro, Itaguaí, v. 15, n. 1, p. 7-19, 1992.

MEDEIROS, L. F. D.; VIEIRA, D. H.; LUNA, M. C. M. de; SOUSA, J. C. D.; COUTINHO, L. de S. Peso ao nascer, prolificidade e mortalidade de caprinos da raça Anglo-nubiana. In: JORNADA DE INICIAÇÃO CIENTÍFICA DA UFRRJ, 7., Seropédica, RJ, Anais...,198, p. 213-214, 1998.

MEDEIROS, L. F. D.; VIEIRA, D. H.; SCHERER, P. O.; LUNA, M. C. M. de; PEREIRA, B. M. Fatores que afetam o período de gestação de cabras da raça Anglo-nubiana, criadas em regime semi-intensivo. In: JORNADA DE INICIAÇÃO CIENTÍFICA DA UFRRJ, 11., Seropédica, RJ, Anais..., v. 11, n. 1, p. 153-154, nov. 2001.

MEDEIROS, L. F. D.; VIEIRA, D. H.; LUNA, M. C. M. de; CABRAL NETO, $\mathrm{O}$. Avaliação de alguns aspectos de desempenho de caprinos da raça Anglo-nubiana, no Estado do Rio de Janeiro. Rev. Univ. Rural, Sér. Ci. Vida, Seropédica, v. 24, n. 2, jul-dez., p. 103-118, 2004.
Os fatores de origem materna (ordem de parição), fetal (número de crias) e ambiental (ano e época de parição) afetaram a duração do período de gestação das cabras.

Existiu uma relação inversa entre o número de crias e a duração da gestação. À medida que aumentou o número de produtos por parto, diminuiu o período de gestação das cabras.

O ano de cobertura e a época de cobertura exerceram influência sobre a taxa de fertilidade das cabras.

As parições ocorreram no segundo semestre do ano, revelando que o sistema de criação não interferiu na parição sazonal dos caprinos exóticos criados na região Centro- Sul do país.

A prolificidade foi influenciada pelo ano, época e ordem de parição.

A prolificidade das cabras da raça Anglo-nubiana é predominantemente de origem dizigótica, podendo ser aumentada com melhoria das condições de meio ambiente.

MOULIN, C. H. S.; MOUCHREK, E. Desempenho reprodutivo de cabras sem raça definida (SRD) no Estado de Minas Gerais. Inf. Agropec., v. 13, n. 146, p. 9-11, 1987.

QURESHI, M. I.; NANAVATIS, S.; BARWE, V.; SAHA, D. N. Study of some reprodutive characteres of local Malvi goats. Indian Vet. J., V. 68, n. 2, p.181-182, 1991.

RIBEIRO, S. D. de A. Criação de caprinos. Ed. São Paulo, Nobel, 1998, 318 p.il.

RIBEIRO, S. D. de A.; RESENDE, K. T. de; RIBEIRO, A. C.; QUEIROZ, S. A.; GONÇALVES, H. C. Índices de desempenho produtivo dos rebanhos usuários do PROCAPRI-Programa Computacional para Gerenciamento para Rebanhos Caprinos. PROCAPRI, Jaboticabal, SP., UNESP. 4 p. (mimeo), 1999.

RODRIGUES DE MEDEIROS, G.; PIMENTA FILHO, E. C., LEITE, S. V. F.; BEZERRA, M. D.; BRITO, E. A. de. Fatores que afetam o período de gestação de cabras nativas e exóticas no semi-árido. In: REUNIÃO ANUAL DA SOCIEDADE BRASILEIRA DE ZOOTECNIA, 34., Juiz de Fora, MG. Anais... Juiz de Fora: Sociedade Brasileira de Zootecnia, p. 278-279, 1997.

RODRIGUES, A. Característica de reprodução, crescimento, mortalidade e produção de leite em caprinos Parda Alemã, Anglo Nubiana e Sem Raça Definida (SRD) nos cariris paraibanos. Areia. PB, UFP, 1988. Tese de Mestrado. 92 p., 1988.

SANCHES RODA, D.; SANTOS, L. E. dos; CUNHA, E. A. da. Aspectos reprodutivos em cabras das raças Moxotó e Anglo-nubiana. $B$. Indústr. Anim. N. Odessa, v. 52, n. 1, p. 57-62, 1995.

SILVA, F. L. R. da; ARAÚJO, A. M. de. Desempenho produtivo em caprinos mestiços no semi-árido do Nordeste do Brasil. Rev. Bras. Zootec., v. 29, n. 4, p. 1028-1035, 2000.

SIMPLÍCIO, A. A.; MACHADO, R.; ALVES, J. U. Manejo reprodutivo de caprinos em regiões tropicais. Sociedade Brasileira de Zootecnia. Caprinocultura e Ovinocultura, SBZ. Piracicaba, SP. FEALQ, p. 33-67, 1990.

SOARES FILHO, G.; McMANUS, C.; MARIANTE, A. da S. Fatores genéticos e ambientais que influenciam algumas características de reprodução e produção de leite em cabras no Distrito Federal. Rev. Bras. Zootec., v. 30, n. 1, p. 133-140, 2001.

SOUZA, C. H. de. Prolificidade, proporção sexual secundária e peso ao nascimento nas raças Anglo-nubiana e Saanen no Ceará, Nordeste Brasileiro. Mossoró: ESAM. 43 p. Monografia. 2001.

VIEIRA, M. E. Q.; ARAÚJO, E. C.; FRANCA, M. P.; SILVA, A. A. da. Productive and reprodutive performance of Moxotó goats in sertão zone of Pernambuco State. In: INTERNATIONAL CONFERENCE OF GOATS, 4., Brasília. Proceedings... Brasília, DF, p. 1334, 1987. 